\title{
Long-Term Outcomes Of Transobturator Tension-Free Vaginal Tapes As Secondary Continence Procedures
}

\section{Authors:}

Dr Mohamed Abdel-Fattah, FRCOG, MD

Senior Clinical Lecturer/ Consultant Urogynaecologist - University Of Aberdeen

Gabriel Cao, B.Sc.

Medical student - University of Aberdeen

Dr Alyaa Mostafa, MD

Research Fellow - University of Aberdeen

Corresponding Author: Dr M. Abdel-Fattah

Senior Lecturer/ Consultant Urogynaecologist

Division of Applied Health Sciences, University of Aberdeen

Address: Second Floor, Aberdeen Maternity Hospital, Foresterhill, Aberdeen, AB25 2ZD

Tel: 01224438424

E-mail: m.abdelfattah@abdn.ac.uk

Article Word Count: 2501 Words

Abstract Word Count: 236 words. 
Key words: Transobturator tapes; Mid-urethral slings; Tension free vaginal tape; Urinary incontinence; Stress urinary incontinence.

\section{Acknowledgments:}

We thank Dr Karmakar (Research Fellow - University of Aberdeen) for sending out the questionnaires and collating the responses. We thank Lindsey Grant for performing the independent data-entry cross-check. A special gratitude goes to all the participants whose excellent co-operation over the years made this study successful.

Funds: The initial phase of this study (up-to 3 years follow-up) was funded by the Henry Smith Charity. Dr Karmakar was funded by IUGA Clinical Fellowship Grant 2014. 


\section{Abstract}

Purpose: To assess the long-term patient reported outcomes following TO-TVT as a secondary continence procedure in women with recurrent stress urinary incontinence (RSUI).

Methods: A secondary analysis of the 9-years follow-up of the E-TOT study: 341 women with predominant SUI symptoms were randomised to undergo either inside-out or outside-in TO-TVT between April 2005 and April 2007. 46 women had R-SUI following previously failed continence surgery and are the basis of this analysis as a one single cohort. Primary outcome was the patient-reported success rate defined as Very/Much improved on Patient's Global Impression of Improvement (PGI-I). Secondary outcomes included late adverse events; impact on women's quality of life and sexual function. Statistical analysis was performed using SPSS v.23.

Results: 63\% completed the 9-year follow-up. The success, based on the PGI-I was 62.1\% with no significant difference between groups (OR: 5.33; 95\%CI: 1.03, 27.76; $\mathrm{p}=0.094$ ). Clinically significant improvement in QoL was found in 84.2\%. Adverse events included vaginal erosions $(n=3)$ and groin pain $(n=2)$. The small sample size is a limitation in this study nevertheless this is one of the largest cohorts reported for women with R-SUI and the first to report the long-term outcomes of TO-TVT as a secondary continence procedure.

Conclusions: TO-TVT operations are associated with good patient-reported success rates (62\%) in women with previous failed continence surgery up-to 9-years. There is a nonsignificant trend towards better outcomes with the Inside-out TO-TVT. 


\section{$\underline{\text { Introduction }}$}

In the UK, the lifetime risk of women undergoing surgery for stress urinary incontinence (SUI) is 3.6\% [1]. The reoperation rate for recurrent SUI (R-SUI) varies between studies $(8.8 \%-17 \%)[2,3]$. The median time to undergo repeat continence surgery for R-SUI in the UK is 2.8 years[4].

Management of R-SUI can be challenging being dependent on multiple factors such as: the type of the index procedure, time-to-failure, and patients' factors such as BMI, comorbidities, and patient's attitude towards further surgery. Surgeons and institution factors are also important such as the availability of surgical expertise and specific investigations (video-urodynamics (VUD), urethral pressure profile (UPP). The Society of Obstetricians and Gynaecologists of Canada recommends the use of conservative management, such as pelvic floor muscle training(PFMT), as a first line treatment in women with R-SUI[5]. There is no consensus on the best surgical management of R-SUI and a number of options have been suggested including midurethral tension-free vaginal slings(MUS) including retropubic tension-free vaginal tape(RP-TVT) and transobturator tension-free vaginal tape (TO-TVT) and more traditional procedures such as colposuspension(CS) and autologous fascial slings(AFS)[6].

A systematic review and meta-analysis in 2013 showed that RP-TVT and TO-TVT were similarly effective in the surgical treatment of women with R-SUI however the authors urged caution in interpretation of the results due to the relatively small number of patients $(n=350)$ and the limited follow-up period (18 month)[4]. 
There is a paucity of data on the long-term outcomes of TO-TVT especially as a secondary continence procedure in women with R-SUI. In the UK, the National Institute for Health and Clinical Excellence(NICE), the Cochrane review in 2015 and most recently the European review(SCENIHR) on surgical meshes in urogynaecological surgery[7-9] have all highlighted the lack of long-term outcomes data for TO-TVT. This study aim to assess the long-term patient reported outcomes in a cohort of women undergoing TO-TVT as a secondary continence procedure within the E-TOT randomised controlled trial (RCT)[10, 11]. We have previously reported the 1-year outcomes in this cohort showing patient-reported success rate of $70 \%$ [12].

\section{Materials and Methods}

A secondary analysis of the E-TOT RCT, performed in a UK tertiary urogynaecological centre in the period of April 2005 to April 2007. Ethical approval was obtained for the longterm follow-up. In the E-TOT study, 341 women were randomly assigned to undergo either Outside-in TOT-ARIS ${ }^{\circledR}$ (Coloplast Corp., Minneapolis, MN, USA) or Inside-out TVT-O ${ }^{\text {TM }}$ (Ethicon Inc., Somerville, NJ, USA). The procedures were performed under general anaesthesia as originally described by Delorme and de-Leval in 2001 and 2003 respectively[13, 14]. The women were included in the E-TOT study if they had urodynamic SUI or mixed UI with predominantly bothersome SUI symptoms, and had declined or failed pelvic floor muscle training. Exclusion criteria included concomitant surgery; uterovaginal prolapse (POPQ score $\geq 2$ ); predominant $\mathrm{OAB}$ symptoms, and neurologic conditions such as multiple sclerosis.

46 women with R-SUI following previous failed continence surgery at time of randomisation were identified and are the basis of this secondary analysis as one single cohort. 
Pre-operative assessment included a detailed history, pelvic examination and urodynamic assessment and completion of symptom severity and QoL questionnaires: King's Health Questionnaire (KHQ)[15]; Birmingham Bowel and Urinary Symptom Questionnaire22(BBUSQ-22)[16] and Pelvic Organ Prolapse/Incontinence Sexual Function Questionnaire(PISQ-12)[17]. Post-operative assessment at the 1-, 3- and 9-years follow-up included, in-addition to the above questionnaires, the Patient Global Impression of Improvement(PGI-I)[18], International Consultation on Incontinence Questionnaire-Short form(ICIQ-SF)[19], and further questions on adverse events (AEs) and further continence surgery.

The primary outcome measured was the patient-reported success rate defined as "very much improved" or "much improved" on the PGI-I, with all other responses classified as failures. Participants who received further continence surgery during the follow-up period were considered as failures. Secondary outcomes included improvement in QoL ( $\geq 18$ points improvement in KHQ score) [20], impact on sexual function (change in PISQ-12 score), and late AEs (such as groin/thigh pain and tape erosions). In-addition, we compared these outcomes between groups.

Statistical analysis was performed using SPSS version 23. Chi-squared or Fisher's exact tests were used to compare categorical variables. Within-group comparison of KHQ scores and PISQ-12 scores were analysed using the Wilcoxon signed rank test while between-group comparison were analysed using the Mann-Whitney U test. The results of the PGI-I at 9-year follow-up were compared to that of 3-year and 1-year follow-up using McNemar's test, at the Bonferroni corrected significant level of 0.025 . All other statistical analyses were performed 
at $5 \%$ significance level in a similar plan to that carried out at 1 and 3 years. We present intention to treat (ITT) and ITT considering women who received further continence surgery as failures.

\section{$\underline{\text { Results }}$}

29/46 women completed the follow-up at 9 years, yielding a response rate (RR) of $63.0 \%$. The CONSORT diagram shows the recruitment and follow-up data up to the 9-year followup for this subgroup(Figure-1). The participants' baseline characteristics did not show significant differences between groups(Table-1).

- Patient-reported success rate:

The patient reported success for the whole cohort, based on the PGI-I and considering participants who had further continence surgery within the follow-up period as failures, was 62.1\%. There was a non-significant trend, towards better outcomes in the inside-out TO-TVT group (Inside-out 80.0\% Vs. Outside-in 42.9\%, OR:5.33;95\%CI:1.03, 27.76, p=0.094) Table2.

Compared to the patient-reported success rate in women undergoing "primary continence surgery” within the same cohort of the E-TOT study [21], there was a non-significant trend to lower success rate in women with R-SUI (62.1\% vs 73.2\%, OR0.60;95\%CI 0.26,1.36, $\mathrm{p}=0.266)$

There was a non-significant trend towards drop in the patient-reported success rate over the years(Figure-2). Comparison of the patient-reported success, and using Bonferroni corrected significance level of $p \leq 0.025$, showed non-significant reduction with time: 1 vs 9 -years and 
3vs 9-years were 69.6\%vs.62.1\%, $\mathrm{p}=0.289$ and $66.7 \%$ vs.62.1\%; $\mathrm{p}=0.999$ respectively. The drop in the success rate was not evident in the inside-out group and this triggered a closer look and sensitivity analysis. Using last observation carried forward (LOCF) for participants with missing outcomes at 9-years; the patient reported success rate for the whole cohort was almost the same (61\%) however the success rate of the inside-out group was considerably lower (68\% vs 80\%)(Table-2).

- $\quad$ Late adverse events:

Pain/ discomfort was reported by 2-participants (both had colposuspension as their index surgery): one participant in the outside-in group, with un-successful outcome ("same" on PGI-I) reported: "groin pain but not sure if related to the procedure”. The other participant was in the inside-out group and reported successful outcome ("much improved” on PGI-I) and chronic right side "back pain" since the operation which affects her day to day activities.

Three participants reported receiving diagnosis and/or treatment of tape erosion/ extrusion at 9-years follow-up; all were in the outside-in group and received surgical excision of the eroded portion of the tape. In 2-participants the index surgery was colposuspension and both had un-successful outcome following TO-TVT within the E-TOT study and subsequently underwent further continence procedures. For the third participant, TO-TVT was also the index procedure and despite surgical excision of eroded part of the tape, she continued to have successful outcome ("Very Much Improved” on PGI-I) at 9-years.

\section{- $\quad$ Impact on QoL}

19 women (65.5\%) completed the KHQ questionnaire at the 9-year follow-up. There were statistically significant improvements in all domains of the KHQ compared to baseline, with 
the exception of general health domain (Table-3). There was a clinically significant improvement in QoL ( $\geq 18$ point improvement in total KHQ score from baseline) in $84.2 \%$ of the women (Outside-in $80.0 \% \%$ vs Inside-out $88.9 \%$, OR 2.00, 95\% CI 0.15 to 26.73, $p>0.999$ ). The result pertained on repeating the analysis based on the $\geq 10$ point improvement score, which was used for analysis at the 1-year follow-up[12].

\section{- Sexual Function}

Only 8 women (27.6\%) completed the PISQ-12 pre-operatively and at 9-year follow-up. The total PISQ-12 score improved in 62.5\% $(n=5)$ and deteriorated in 37.5\% $(n=3)$ (Table-3).

\section{$\underline{\text { Discussion }}$}

This is the first clinical trial to report on the long-term outcomes of TO-TVT as a secondary continence procedure in the management of R-SUI in women. Despite the relatively small sample size, it's the one of the largest cohorts exploring the outcomes of TO-TVT as a secondary continence procedure and the first to report the long-term outcomes.

Our results showed a patient-reported success of $62.1 \%$ at a median of 9-years follow-up; the success rate pertained on sensitivity analysis using LOCF.

We used the PGI-I as the primary outcome as it provides a robust validated and more global review of the treatment outcome and is more encompassing of the range of benefits and potential harm[23]. We considered women who had any outcome apart from "very/much improved" as un-successful to avoid overestimation of the success rate. The success rate in our study was higher than a recent systematic review by Nikolopoulos et al[24], they reported 
that the overall pooled success rates for TO-TVT following previous failed MUS was 55.4\% (31/56) compared to $72.8 \%$ (174/239) for RP-TVT. A significant limitation in the latter review was the large variation in the duration of the follow-up which ranged from 15 to 42 months.

The 2015 Cochrane systematic review of MUS[8] highlighted the trend towards drop in the patient-reported success rate over time for all types of continence surgery. Similar trend was seen in our study (69.6\% at 1-year vs $62.1 \%$ at 9-years). Interestingly this trend was not seen in women within the inside-out TO-TVT group except after sensitivity analysis. The sizeable and differential fall in the participants' response rate overtime in the inside-out group triggered a closer look by our team. This revealed that a significant percentage of women with unsuccessful outcome at 3-years failed to respond at 9-years. This highlights the importance of sensitivity analysis, using different assumptions for those with missing outcomes, to improve the confidence in the results of long-term follow-up clinical trials.

Compared to TO-TVT as "primary continence surgery"[21] there was a clear trend towards lower patient-reported success in women undergoing TO-TVT as a secondary procedure. This trend failed to reach statistical significance which may be due to type-2 error secondary to the relatively small sample size. Our results are consistent with Stav et al[25] who assessed 77 women with repeat MUS surgery and a minimum follow-up of 4-years; the patientreported success rate was $86 \%$ and $62 \%$ for primary and repeat MUS respectively $(\mathrm{p}<0.001)$.

Our results at 1 and 9-years showed a clear, though non-significant, trend towards higher patient-reported success rate in the inside-out group. The trend pertained on sensitivity analysis using LOCF but did not reach statistical significance presumably due to the small 
size cohort. This finding is difficult to explain as the surgeons within the E-TOT study were quite experienced in both techniques of TO-TVT, the baseline patients' characteristics were not statistically different and the procedures are fairly similar. A possible explanation for the higher success rate in the "inside-out" route would be the limited dissection behind the inferior pubic ramus which may contribute to better fixing of the tape in position and consequent better urethral support and long-term resilience of the procedure.

Little is known on the long-term AE of TO-TVT as a secondary continence procedure. Ford et al[8] reported low rates of groin pain following MUS, mostly were short-lasting and resolving within 6 months after the operation. It is therefore an important finding that 2participants in our study reported pain/discomfort at the 9-year follow-up. We acknowledge the limitation of the data on pain as there is uncertainty on its relation to the procedure especially with the lack of control group without surgery. Nevertheless chronic groin pain is a known complication for TO-TVT; Teo et al[26] reported $26 \%$ leg pain in the immediate postoperative period and Zhang et al[27] reported $6.4 \%$ groin pain at 7-years following inside-out TO-TVT.

In this cohort, the rate of the vaginal tape erosion with TO-TVT as secondary continence procedures is relatively high in contrast to the rate of (24:1000) from the Cochrane review by Ford et al. Participants reported if they have been diagnosed with tape erosion, and treatment received if any, hence the reported rate excludes asymptomatic tape erosions. This is an interesting finding that was not previously reported in the literature; The index surgery in 2/3 participants was colposuspension hence an index "tape" surgery and consequent fibrosis could not be blamed for this relatively high erosion rate. The relatively high AE rate in this 
special cohort of women could not be generalised for women undergoing TO-TVT as primary procedures.

Our study is the first to assess the long-term QoL and sexual function in women who underwent TO-TVT as secondary continence surgery however the small sample size is a limitation. QoL and sexual function are usually difficult to address at long-term follow-up as many confounding factors may affect the results such as age, change in patients' priorities, and developing other health conditions. For sexual function, there are more confounding factors including vaginal dryness, development of prolapse and even partner-related problems can affect the PISQ-12 scores. We previously reported that $76 \%$ of women showed clinically improvement in QoL based on the $\geq 10$ point improvement in KHQ score at 1-year follow-up. At 9-year follow-up, we used the relatively newer cut-off value of $\geq 18$ point improvement for clinically significant improvement[20] and the original cut-off value of $\geq 10$ point [28]. Both showed similar results with the majority of women (84\%) reporting improvement in their QoL. The sexual function questionnaire could only be assessed in 8-women in our study which is too small to draw a meaningful conclusion. Nevertheless there was a trend for two third of women to report improvement in their sexual function while one third reported deterioration. Zhang et al. reported similar results for sexual function in women treated with TO-TVT procedure at 7-years follow-up[27].

Our results are consistent with the literature on MUS in women with previous continence surgery however it's obviously debatable if $62 \%$ long-term success rate is acceptable. There is paucity in the literature that can guide us on how to improve the outcome of surgery in this special cohort of women; this is further complicated by the lack of understanding for the aetiology of R-SUI. The Cochrane review previously showed the lack of data to recommend 
any of the different management strategies for R-SUI after failed MUS[22]. In a multivariate analysis, we have previously shown MUCP $<30 \mathrm{cmH} 2 \mathrm{O}$ to be the only independent risk factor for failure of TO-TVT as secondary continence procedure (OR 9.206, 95\%CI1.511,56.104)[12] Liapis et al [29] however showed that low-MUCP did not affect the success rates of repeat RP-TVT while a combination of low-MUCP and limited urethral mobility were associated with significantly reduced success rate.

Nevertheless, pre-operative urodynamics is mandatory prior to embarking on a repeat continence procedure with the aim to ascertain the diagnosis. Special tests such as VUD and UPP can be helpful in choosing the correct subsequent procedure[6]. The authors recommend that secondary continence procedures should only be performed in tertiary centres with expertise in assessment and management of these patients. These centres should collaborate in sharing their data and in well-designed clinical trials to assess the most effective investigations and management strategies.

- Strengths and limitations:

This is the first clinical trial to report on the long-term outcomes of TO-TVT as a secondary continence procedure. The trend towards better patient-reported outcomes with the inside-out TO-TVT is a novel and important finding.

There was no risk of assessor bias in this study, as the 9-year follow-up was done through a postal questionnaire and all the outcomes were assessed using validated questionnaires. However, the study has its limitations, the relatively small cohort size which is a limitation in any study reporting on surgical treatment for women with R-SUI due to relative rarity of the disease. This is especially relevant to between-group comparisons in this study with 
possibility of type-2 error. In-addition, there was a differential loss to follow-up in one group, despite our attempts to minimise attrition; this was overcome by sensitivity analysis.

\section{Conclusion:}

TO-TVT operations are associated with good patient-reported success rate (62\%) in women with previous failed continence surgery up-to 9-years. There is a non-significant trend towards better outcomes with the Inside-out TO-TVT. 


\section{Authors contributions:}

For this long-term study:

- Mohamed Abdel-fattah and Alyaa Mostafa: conceived the idea; obtained funding; secured the ethics and institutional approvals.

- Alyaa Mostafa and Gabriel Cao: data collection

- Gabriel Cao: data entry and data analysis.

- Alyaa Mostafa and Lindsey Grant (trial co-ordinator): performed 100\% crosschecking of the data entry.

- Gabriel Cao: arranged review of the statistics analysis plan with the statistics clinic in University of Aberdeen

- Alyaa Mostafa supervised the data analysis.

- Gabriel Cao and Mohamed Abdel-fattah: manuscript writing

- All authors critically reviewed the manuscript and approved it

- All authors take full responsibility for the integrity of the study and the data presented.

\section{Disclosure of interests:}

- Dr Abdel-Fattah has previously delivered paid lectures and/or training courses for Bard, Coloplast, AMS, Pfizer and Astellas. He received travel grants from different pharmaceutical companies to attend medical conferences in the past. University of Aberdeen received research grant from Coloplast in 2009.

- Dr Alyaa Mostafa received travel award from the International Continence Society (ICS) to attend the ICS annual conference in 2012.

- Gabriel Cao received a travel award from UKCS to attend the UKCS annual conference in 2016. 


\section{Ethical Details:}

The study timely received all required approvals from Research \& Development Departments in Glasgow \& Aberdeen and the relevant ethics committee WOSRES (Ref05/S0702/6) and was registered on www.clinicaltrials.gov (NCT00136071) in 2005. 


\section{Figure legends}

Figure 1: CONSORT diagram of patients recruited and follow-up

Figure 2: Graph showing the PGI-I success rate at 1-year, 3-year and 9-year followup

\section{References}

1. Abdel-Fattah M, Familusi A, Fielding S, Ford J, Bhattacharya S. Primary and repeat surgical treatment for female pelvic organ prolapse and incontinence in parous women in the UK: a register linkage study. BMJ Open 2011: 1:e000206

2. Denman MA, Gregory WT, Boyles SH, Smith V, Edwards SR, Clark AL. Reoperation 10 years after surgically managed pelvic organ prolapse and urinary incontinence. Am J Obstet Gynecol 2008: 198:555.e1,555.e5

3. Fialkow M, Symons RG, Flum D. Reoperation for urinary incontinence. Am J Obstet Gynecol 2008: 199:546.e1,546.e8

4. Agur W, Riad M, Secco S, et al. Surgical treatment of recurrent stress urinary incontinence in women: a systematic review and meta-analysis of randomised controlled trials. Eur Urol 2013: 64:323-36

5. Lovatsis D, Easton W, Wilkie D, Society of Obstetricians and Gynaecologists of Canada Urogynaecology Committee. Guidelines for the evaluation and treatment of recurrent urinary incontinence following pelvic floor surgery. J Obstet Gynaecol Can 2010: 32:893-904

6. Nadeau G, Herschorn S. Management of recurrent stress incontinence following a sling. Curr Urol Rep 2014: 15:427,014-0427-0 
7. National Institute for Health and Clinical Excellence(NICE). Urinary Incontinence: The management of Urinary Incontinence in Women. 2013: september

8. Ford AA, Rogerson L, Cody JD, Ogah J. Mid-urethral sling operations for stress urinary incontinence in women. Cochrane Database Syst Rev 2015: 7:CD006375

9. Scientific Committee on Emerging and Newly Identified Health Risks (SCENIHR).

Opinion on: The safety of surgical meshes used in urogynecological surgery

2015: 2015

10. Abdel-Fattah M, Ramsay I, Pringle S, et al. Randomised prospective single-blinded study comparing 'inside-out' versus 'outside-in' transobturator tapes in the management of urodynamic stress incontinence: 1-year outcomes from the E-TOT study. BJOG 2010: 117:870-8

11. Abdel-Fattah M, Mostafa A, Familusi A, Ramsay I, N'dow J. Prospective randomised controlled trial of transobturator tapes in management of urodynamic stress incontinence in women: 3-year outcomes from the Evaluation of Transobturator Tapes study. Eur Urol 2012: 62:843-51

12. Abdel-Fattah M, Ramsay I, Pringle S, et al. Evaluation of Transobturator Tension-free Vaginal Tapes in Management of Women With Recurrent Stress Urinary Incontinence. Urology 2011:

77:1070-5

13. Delorme E. Transobturator urethral suspension: mini-invasive procedure in the treatment of stress urinary incontinence in women. Prog Urol 2001: 11:1306-13

14. de Leval J. Novel surgical technique for the treatment of female stress urinary incontinence: transobturator vaginal tape inside-out. Eur Urol 2003: 44:724-30 
15. Kelleher CJ, Cardozo LD, Khullar V, Salvatore S. A new questionnaire to assess the quality of life of urinary incontinent women. Br J Obstet Gynaecol 1997: 104:1374-9

16. Hiller L, Bradshaw HD, Radley SC, Radley S. A scoring system for the assessment of bowel and lower urinary tract symptoms in women. BJOG 2002: 109:424-30

17. Rogers RG, Coates KW, Kammerer-Doak D, Khalsa S, Qualls C. A short form of the Pelvic Organ Prolapse/Urinary Incontinence Sexual Questionnaire (PISQ-12). Int Urogynecol J Pelvic Floor Dysfunct 2003: 14:164,8; discussion 168

18. Yalcin I, Bump RC. Validation of two global impression questionnaires for incontinence. Am J Obstet Gynecol 2003: 189:98-101

19. Avery K, Donovan J, Peters TJ, Shaw C, Gotoh M, Abrams P. ICIQ: a brief and robust measure for evaluating the symptoms and impact of urinary incontinence. Neurourol Urodyn 2004: 23:322-30

20. Abdel-fattah M, Hasafa Z, Mostafa A. Correlation of three validated questionnaires for assessment of outcomes following surgical treatment of stress urinary incontinence in women. Eur J Obstet Gynecol Reprod Biol 2011: 157:226-9

21. Karmakar D, Mostafa A, Abdel-fattah M. Long-Term Patient-Reported Outcomes Of Transobturator Tapes In Women With Stress Urinary Incontinence. BJOG -under review for publication 2016:

22. Bakali E, Buckley BS, Hilton $P$, Tincello DG. Treatment of recurrent stress urinary incontinence after failed minimally invasive synthetic suburethral tape surgery in women. Cochrane Database Syst Rev 2013: 2:CD009407 
23. Cartwright R, Brown H, Rizk D. Patient reported outcome measures after incontinence and prolapse surgery: are the pictures painted by the ICIQ and PGI-I accurate? Int Urogynecol J 2016: 27:507-8

24. Nikolopoulos KI, Betschart C, Doumouchtsis SK. The surgical management of recurrent stress urinary incontinence: a systematic review. Acta Obstet Gynecol Scand 2015: 94:568-76

25. Stav K, Dwyer PL, Rosamilia A, et al. Repeat synthetic mid urethral sling procedure for women with recurrent stress urinary incontinence. J Urol 2010: 183:241-6

26. Teo R, Moran P, Mayne C, Tincello D. Randomized trial of tension-free vaginal tape and tensionfree vaginal tape-obturator for urodynamic stress incontinence in women. J Urol 2011: 185:1350-5

27. Zhang Z, Zhu L, Xu T, Lang J. Retropubic tension-free vaginal tape and inside-out transobturator tape: a long-term randomized trial. Int Urogynecol J 2016: 27:103-11

28. Kelleher CJ, Pleil AM, Reese PR, Burgess SM, Brodish PH. How much is enough and who says so? BJOG 2004: 111:605-12

29. Liapis $A$, Bakas $P$, Creatsas $G$. Tension-free vaginal tape in the management of recurrent urodynamic stress incontinence after previous failed midurethral tape. Eur Urol 2009: 55:1450-5 
Figure 1: CONSORT

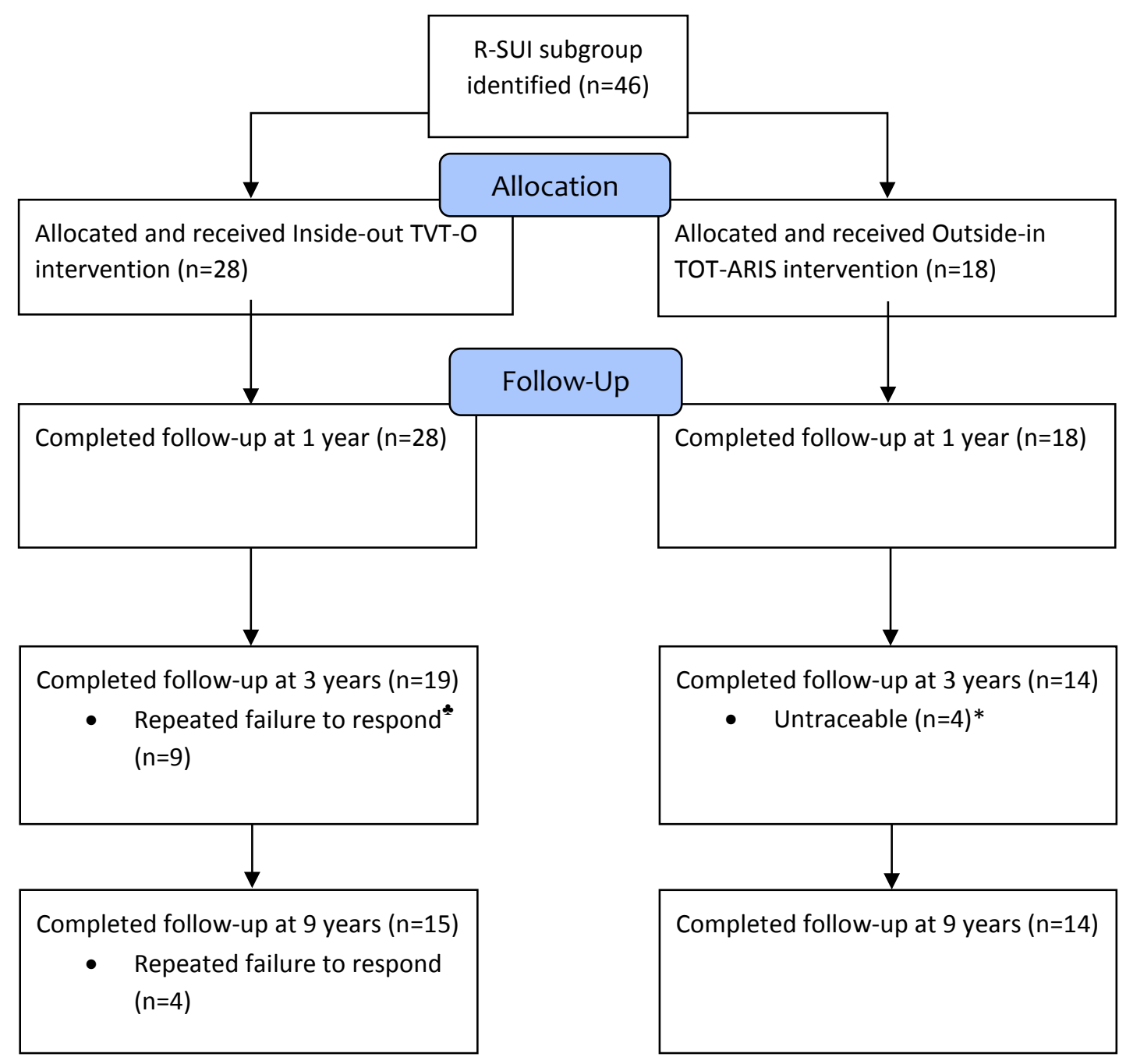

"Participant failed to respond to follow-up questionnaires however her correct postal address was confirmed.

*Postal questionnaires returned as in-correct address and correct address could not be established (e.g. patient moved address, moved abroad, etc ) 
Patient-reported success rate over the 9 years

Figure 2

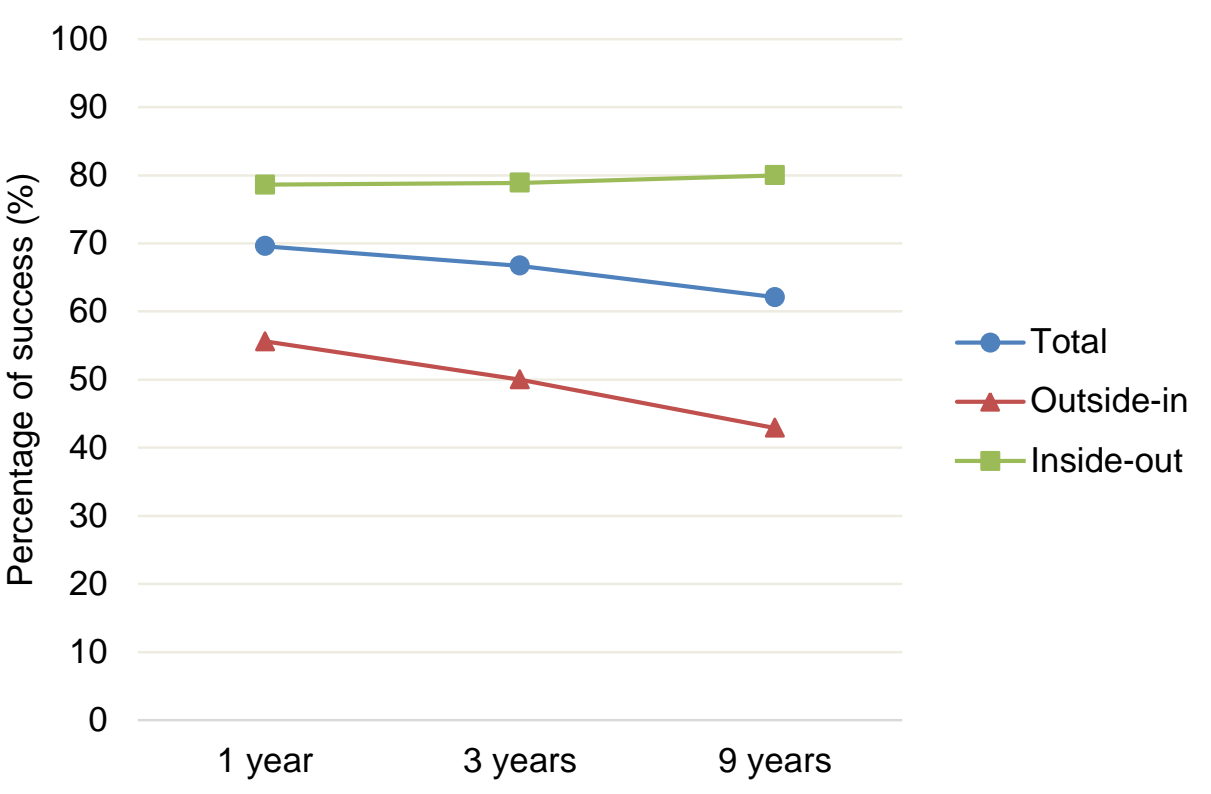


Table 1 Baseline characteristics of patients

\begin{tabular}{|c|c|c|c|c|}
\hline & $\begin{array}{l}\text { Whole cohort } \\
n=29\end{array}$ & $\begin{array}{l}\text { Outside-in } \\
n=14\end{array}$ & $\begin{array}{l}\text { Inside-out } \\
n=15\end{array}$ & $p$-value \\
\hline Mean age \pm SD & $55.62 \pm 9.673$ & $58.98 \pm 9.946$ & $52.46 \pm 8.562$ & 0.069 \\
\hline Mean BMI \pm SD & $28.72 \pm 4.765$ & $29.86 \pm 5.709$ & $27.67 \pm 3.559$ & 0.232 \\
\hline $\begin{array}{l}\text { Mixed Incontinence } \\
\text { (MUI) }\end{array}$ & $6(20.7 \%)$ & $3(21.4 \%)$ & $3(20.0 \%)$ & 0.639 \\
\hline MUCP $<30 \mathrm{Cm}$ H2O & $7(24.1 \%)$ & $4(28.6 \%)$ & $3(20.0 \%)$ & 0.458 \\
\hline $\begin{array}{l}\text { Previous } \\
\text { hysterectomy }\end{array}$ & $14(48.3 \%)$ & $8(57.1 \%)$ & $6(40.0 \%)$ & 0.581 \\
\hline $\begin{array}{l}\text { Previous anterior } \\
\text { repair }\end{array}$ & $1(3.4 \%)$ & $1(7.1 \%)$ & $0(0 \%)$ & 0.483 \\
\hline \multicolumn{5}{|c|}{ Previous incontinence surgery } \\
\hline Colposuspension & $11(37.9 \%)$ & $6(42.9 \%)$ & $5(33.3 \%)$ & 0.885 \\
\hline RP-TVT & $13(44.8 \%)$ & $6(42.9 \%)$ & $7(46.7 \%)$ & $>0.999$ \\
\hline TO-TVT & $5(17.2 \%)$ & $2(14.3 \%)$ & $3(20.0 \%)$ & $>0.999$ \\
\hline
\end{tabular}

MUCP = Maximum Urethral Closure Pressure

$\mathrm{BMI}=$ Body Mass Index 
Table 2: Patient-reported success at 9-year follow-up \& Sensitivity analysis

\begin{tabular}{|llllll}
\hline & $\begin{array}{l}\text { Total } \\
\text { number (\%) }\end{array}$ & $\begin{array}{l}\text { Outside-in } \\
\text { (\%) }\end{array}$ & $\begin{array}{l}\text { Inside-out } \\
\text { (\%) }\end{array}$ & OR (95\% Cl) & $\begin{array}{l}\text { p- } \\
\text { value }\end{array}$ \\
\hline PGI-I $^{*}$ & $20 / 29(69.0)$ & $8 / 14(57.1)$ & $12 / 15(80.0)$ & $3.00(0.58,15.61)$ & 0.245 \\
\hline PGI-I $^{\#}$ & $18 / 29(62.1)$ & $6 / 14(42.9)$ & $12 / 15(80.0)$ & $5.33(1.03,27.76)$ & 0.094 \\
\hline $\begin{array}{l}\text { Sensitivity analysis based on PGI-I } \\
\text { Assume all missing } \\
\text { data as failure }\end{array}$ & $18 / 46(39.1)$ & $6 / 18(33.3)$ & $12 / 28(42.9)$ & $1.50(0.44,5.15)$ & 0.737 \\
\hline $\begin{array}{l}\text { Last observation } \\
\text { carried forward }\end{array}$ & $28 / 46(60.9)$ & $9 / 18(50.0)$ & $19 / 28(67.9)$ & $2.1(0.63,7.13)$ & 0.367 \\
\hline
\end{tabular}

PGI-I success defined as "very much" or "much improved"

Intention-to-treat analysis (ITT)

\# Intention-to-treat analysis (ITT) considering women who had further continence surgery as failures 
Table 3: Comparison of KHQ and PISQ-12 scores between pre-operative and 9-year follow-up and between Outside-in and Inside-out procedures

\begin{tabular}{|c|c|c|c|c|c|c|c|}
\hline & \multicolumn{2}{|l|}{ Median (IQR) } & \multirow[t]{2}{*}{ p-value } & \multicolumn{2}{|c|}{ Median difference (IQR) } & \multirow[t]{2}{*}{$p$-value } \\
\hline & & Pre-op & 9-year post op & & Outside-in & Inside-out & \\
\hline \multirow[t]{9}{*}{$\begin{array}{l}\text { KHQ } \\
\text { domains }\end{array}$} & General health & $\begin{array}{l}25.00 \\
(25.00,37.50)\end{array}$ & $\begin{array}{l}25.00 \\
(6.25,50.0)\end{array}$ & $>0.999$ & $\begin{array}{l}0.00 \\
(0.00,0.00)\end{array}$ & $\begin{array}{l}0.00 \\
(-12.50,12.50)\end{array}$ & $>0.999$ \\
\hline & $\begin{array}{l}\text { Incontinence } \\
\text { impact }\end{array}$ & $\begin{array}{l}100.00 \\
(100.0,100.0)\end{array}$ & $\begin{array}{l}33.33 \\
(0.00,50.0)\end{array}$ & $<0.001$ & $\begin{array}{l}33.33 \\
(0.00,66.67)\end{array}$ & $\begin{array}{l}83.33 \\
(41.67,100.0)\end{array}$ & 0.085 \\
\hline & Role limitation & $\begin{array}{l}83.33 \\
(58.33,100.0)\end{array}$ & $\begin{array}{l}8.33 \\
(0.00,50.0)\end{array}$ & 0.001 & $\begin{array}{l}33.33 \\
(16.67,100.0)\end{array}$ & $\begin{array}{l}66.67 \\
(0.00,91.67)\end{array}$ & 0.930 \\
\hline & $\begin{array}{l}\text { Physical } \\
\text { limitation }\end{array}$ & $\begin{array}{l}66.67 \\
(50.00,100.0)\end{array}$ & $\begin{array}{l}16.67 \\
(0.00,33.33)\end{array}$ & $<0.001$ & $\begin{array}{l}41.67 \\
(12.5087 .50)\end{array}$ & $\begin{array}{l}50.00 \\
(8.33,66.67)\end{array}$ & 0.975 \\
\hline & $\begin{array}{l}\text { Social } \\
\text { limitation }\end{array}$ & $\begin{array}{l}55.56 \\
(33.33,72.22)\end{array}$ & $\begin{array}{l}0.00 \\
(0.00,11.11)\end{array}$ & 0.002 & $\begin{array}{l}33.33 \\
(0.00,100.0)\end{array}$ & $\begin{array}{l}50.00 \\
(11.11,75.00)\end{array}$ & 0.926 \\
\hline & $\begin{array}{l}\text { Personal } \\
\text { limitation }\end{array}$ & $\begin{array}{l}33.33 \\
(0.00,75.00)\end{array}$ & $\begin{array}{l}0.00 \\
(0.00,33.33)\end{array}$ & 0.008 & $\begin{array}{l}33.33 \\
(-16.67,66.67)\end{array}$ & $\begin{array}{l}18.83 \\
(6.75,45.50)\end{array}$ & 0.887 \\
\hline & Emotions & $\begin{array}{l}77.78 \\
(61.11,100.0)\end{array}$ & $\begin{array}{l}0.00 \\
(0.00,44.44)\end{array}$ & $<0.001$ & $\begin{array}{l}44.44 \\
(0.00,77.78)\end{array}$ & $\begin{array}{l}77.78 \\
(16.67,88.89)\end{array}$ & 0.365 \\
\hline & Sleep/ energy & $\begin{array}{l}66.67 \\
(33.33,83.33)\end{array}$ & $\begin{array}{l}33.33 \\
(0.00,62.50)\end{array}$ & 0.005 & $\begin{array}{l}33.33 \\
(-16.67,50.0)\end{array}$ & $\begin{array}{l}16.67 \\
(0.00,58.33)\end{array}$ & 0.792 \\
\hline & $\begin{array}{l}\text { Severity } \\
\text { measure }\end{array}$ & $\begin{array}{l}91.67 \\
(66.67,100.0)\end{array}$ & $\begin{array}{l}25.00 \\
(0.00,75.00)\end{array}$ & 0.001 & $\begin{array}{l}58.33 \\
(-8.33,75.00)\end{array}$ & $\begin{array}{l}54.17 \\
(4.17,93.75)\end{array}$ & 0.757 \\
\hline \multicolumn{2}{|l|}{ Total KHQ } & $\begin{array}{l}66.36 \\
(56.42,76.52)\end{array}$ & $\begin{array}{l}16.67 \\
(2.78,23.46)\end{array}$ & $<0.001$ & $\begin{array}{l}30.86 \\
(13.81,68.52)\end{array}$ & $\begin{array}{l}54.51 \\
(23.61,64.85)\end{array}$ & 0.806 \\
\hline \multicolumn{2}{|c|}{ Total PISQ-12 } & $\begin{array}{l}33.50 \\
(24.00,36.00)\end{array}$ & $\begin{array}{l}35.00 \\
(27.00,37.00)\end{array}$ & 0.575 & $\begin{array}{l}3.00 \\
(-4.25,9.50)\end{array}$ & $\begin{array}{l}-0.50 \\
(-6.50,11.50)\end{array}$ & 0.663 \\
\hline
\end{tabular}

